Alireza Khoshkbar Sadeghi and Maryam Farbodi*

\title{
Preparation of polyaniline-polyvinyl alcohol- silver nanocomposite and characterization of its mechanical and antibacterial properties
}

https://doi.org/10.1515/secm-2016-0329

Received November 2, 2016; accepted August 27, 2017; previously published online February 21, 2018

Abstract: In the present research, polyaniline is used as a conducting polymer and polyvinyl alcohol is also used as a biopolymer, because of its mechanical properties and suitable processability. Also, silver nanoparticles are considered as a reinforcing agent of thermal stability, mechanical and antibacterial properties to prepare polyaniline-polyvinyl alcohol-silver nanocomposite. The synthesis of polyaniline-polyvinyl alcohol composite and polyaniline-polyvinyl alcohol-silver nanocomposite is performed through addition of polyaniline and silver in polyvinyl alcohol solution. In order to review thermal, mechanical and antibacterial properties of synthesized composite and nanocomposites, components with different weight rates are used. The obtained results from thermogravimetric analysis (TGA) tests also indicate promotion of thermal stability of polyaniline-polyvinyl alcohol-silver nanocomposite compared with pure polyvinyl alcohol in temperatures above $400^{\circ} \mathrm{C}$. The results of Fourier-transform infrared (FTIR) spectroscopy revealed the presence of polyaniline, polyvinyl alcohol and silver in the structure of polyaniline-polyvinyl alcohol-silver triple nanocomposite film. The obtained results from a review of antibacterial properties showed that polyaniline-polyvinyl alcohol-silver nanocomposites have antibacterial effects on two different types of Gram-positive and Gramnegative bacteria. The obtained results from a review of mechanical properties of nanocomposites showed that the greatest value of tensile strength (13.8 $\mathrm{MPa}$ ) belonged to polyaniline-polyvinyl alcohol-silver $(88 \% / 9 \% / 3 \% \mathrm{w} / \mathrm{w})$ nanocomposites. Therefore, this is determined as an optimal triple nanocomposite. In addition, scanning electron

\footnotetext{
*Corresponding author: Maryam Farbodi, Department of Chemistry, East Azarbayjan Science and Research Branch, Islamic Azad University, Tabriz, Iran; and Department of Chemistry, Tabriz Branch, Islamic Azad University, Tabriz, Iran, e-mail: m.farbodi@iaut.ac.ir Alireza Khoshkbar Sadeghi: Department of Chemistry, East Azarbayjan Science and Research Branch, Islamic Azad University, Tabriz, Iran; and Department of Chemistry, Tabriz Branch, Islamic Azad University, Tabriz, Iran
}

microscopy (SEM) coupled with an energy dispersive $\mathrm{X}$-ray (EDX) system was used to characterize the composition and structure of polyaniline-polyvinyl alcohol-silver nanocomposite film.

Keywords: antibacterial; nanocomposites; polyaniline; polyvinyl alcohol; silver.

\section{Introduction}

Any polymer which has electrical, electronical and optical properties of the metals and keeps its mechanical properties and other properties of general polymers is known as an inherently conducting polymer. Conducting polymers, including polyaniline, have interesting electric conductivity, optical, and electro-activity properties. These polymers and their composites have been frequently applicable in electronic, aeronautic, and military industries, as well as sensors, absorption of heavy elements, and adsorption of the organic pigments from solutions. In the protonated state, although polyaniline has a good conductivity, it has weak mechanical and processing properties (solubility in solvents, the possibility to melt and mold). Reinforcing the mentioned properties and its thermal resistance property is necessary for expanding its use in the industries $[1,2]$.

One of the common strategies for reinforcing the mechanical and processing properties of polyaniline is preparing its composites using common polymers and biopolymers. For example, preparing polyaniline composites using polymers such as epoxy [3], polystyrene [4], and polyvinyl chloride [5] has been reported. Polyaniline- biopolymer composites are a new class of advanced polymeric materials with unique physicochemical properties $[6,7]$. They are mainly prepared with the purpose of application in manufacturing biosensors such as preparing polyaniline composites with polyvinyl alcohol [6] and chitosan [7]. Meanwhile, polyvinyl alcohol is the most common type of synthetic polymer. It is soluble in water and is obtained by polymerization of vinyl acetate monomer and its hydrolysis into polyvinyl alcohol. Its polar nature, solubility in water, non-toxicity, high tensile strength, and favorable adherence properties has turned it into a good candidate for 
preparing conducting polymer composites. Despite the acceptable efficiency of composite technology in preparing materials with enhanced properties, in most cases, the obtained composite cannot meet the industrial needs in providing favorable mechanical properties. In recent years, researchers have found that if materials are prepared at small scales, the bonds between the materials and the surrounding phases are much stronger than if they are prepared at large scales. Therefore, a new type of composite called nanocomposite has been introduced and developed.

In polymer-based nanocomposites, inorganic materials at the nano scale with different structures are used in polymer matrices, and serve as reinforcement agents with very low weight percentages ( wt $\% ;<6 \%)$. Some examples are the production of polyaniline nanocomposites with metal oxides [8], carbon nanotubes [9], graphite [10], montmorillonite [11], and silver [12]. For example, carbon nanotubes are used as ideal additives for the preparation of polymer-based nanocomposites due to their extraordinary properties such as high mechanical strength, high aspect ratio, small diameter, light weight, high electrical and thermal conductivities, and high thermal and air stabilities. Therefore, polymer nanocomposites, which are regarded as organic-inorganic hybrids because of possessing the properties of both organic and inorganic compounds, have attracted the attention of researchers as a new research area. It seems that the integration of the two proposed strategies or simultaneous use of the conventional polymers and the nano-structures such as silver for producing threepart hybrid nanocomposites can have more desirable results in improving the mechanical properties and processability of polyaniline.

A review of related literature indicates that there are a limited number of reports on preparing three-part hybrid nanocomposites from polyaniline. As an example, the hybrid nanocomposites of polyaniline-polyvinyl chloride$\mathrm{ZnO}$, and polyaniline-epoxy-Zn were prepared by Olad and Nosrati [13] and Olad et al. [14] and their performance as anti-corrosive coating was studied by creating thin layer coatings on iron coupons in different corrosive environments. The obtained results indicated better performance for three-part hybrid coatings in comparison with the pure polyaniline.

Therefore, in the present study, the three-part hybrid nanocomposites of polyaniline-polyvinyl alcohol-silver are prepared with different $\mathrm{wt} \%$ for the first time in order to improve the antibacterial morphological, and mechanical properties, thermal resistance and the processability of polyaniline.

\section{Materials and methods}

\subsection{Chemicals}

Polyvinyl alcohol 98\%, silver nanoparticles, ammonium persulfate, and $\mathrm{HCl} 37 \%$ were purchased from Merck Company of Germany. Polyaniline was prepared according to reference [4].

\subsection{Preparation of polyaniline-polyvinyl alcohol composite}

For preparing polyaniline-polyvinyl alcohol composite with wt $\%$ of $90-10 \%, 0.54 \mathrm{~g}$ of polyvinyl alcohol (90 wt $\%$ ) was dissolved in $40 \mathrm{ml}$ distilled water. Then, $0.06 \mathrm{~g}$ (10 wt $\%)$ polyaniline was added to the solution and put in a bath of Ultrasonic (Lbs2 model-made by FALC) for $30 \mathrm{~min}$. It was stirred for $30 \mathrm{~min}$. The above-mentioned method was used for preparing the composite of polyvinyl alcohol-polyaniline with the wt $\%$ of $80-20 \mathrm{wt} \%$, and only the amount of the raw materials changed proportionate to the new wt $\%$. The synthesized samples labeled as 8 and 9 are given in Table 1.

\subsection{Preparation of polyvinyl alcohol-silver nanocomposite}

Some $0.549 \mathrm{~g}$ (99 wt\%) of polyvinyl alcohol was solved in $40 \mathrm{ml}$ of distilled water. Then, $1 \mathrm{wt} \%$ of silver nanoparticles $(0.006 \mathrm{~g})$ was added to it, and put in a bath of Ultrasonic (Lbs2 model) for $30 \mathrm{~min}$. It was stirred for $30 \mathrm{~min}$. The above-mentioned method was used for preparing the nanocomposites of polyvinyl alcohol-silver including

Table 1: Weight percentages of prepared samples.

\begin{tabular}{lrrr}
\hline Samples & Polyvinyl alcohol & Polyaniline & Silver \\
\hline 1 & 100 & 0 & 0 \\
2 & 89 & 10 & 1 \\
3 & 79 & 20 & 1 \\
4 & 88 & 9 & 3 \\
5 & 78 & 19 & 3 \\
6 & 87 & 8 & 5 \\
7 & 77 & 18 & 5 \\
8 & 90 & 10 & 0 \\
9 & 80 & 20 & 0 \\
10 & 99 & 0 & 1 \\
11 & 97 & 0 & 3 \\
12 & 95 & 0 & 5 \\
\hline
\end{tabular}


$1 \mathrm{wt} \%, 3 \mathrm{wt} \%$, and $5 \mathrm{wt} \%$ of silver. The obtained samples labeled as 10, 11, and 12 are given in Table 1.

\subsection{Preparation of polyvinyl alcohol- polyaniline-silver nanocomposite}

Some $0.54 \mathrm{~g}(90 \mathrm{wt} \%)$ of polyvinyl alcohol was solved in $40 \mathrm{ml}$ of distilled water. Then, $0.054 \mathrm{~g}$ of synthesized polyaniline ( $9 \mathrm{wt} \%$ ) was added to the solution. After adding

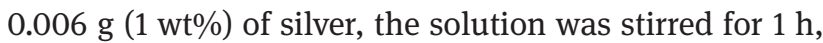
and the solution was put in an ultrasonic bath for $30 \mathrm{~min}$. The above-mentioned method was used for preparing the nanocomposites of polyvinyl alcohol-polyaniline-silver including silver ( $1 \mathrm{wt} \%, 3 \mathrm{wt} \%$ and $5 \mathrm{wt} \%$ ) and polyaniline (9 $\mathrm{wt} \%$ and $19 \mathrm{wt} \%$ ). The synthesized samples, labeled as 2-7, are given in Table 1.

\subsection{Preparation of composite and nanocomposite films}

After preparing the samples, as described in 2.2, 2.3 and 2.4, the obtained solutions were put inside the plate with a diameter of $10 \mathrm{~cm}$, and after evaporation of the solution by oven drying at $50^{\circ} \mathrm{C}$, the prepared film was removed from the plate.

\subsection{Characterization}

Fourier-transform infrared (FTIR) spectroscopy using Shimadzu 8400 S (Japan) was used to record the FTIR spectra of silver nanoparticles, pure polyaniline, polyvinyl alcohol and the optimal nanocomposite film. Scanning electron microscopy (SEM) using LEO 1430VP (corporately made by Germany and England) was used to investigate the surface morphology of prepared films. Thermogravimetric analysis (TGA) for silver nanoparticles, pure polyaniline, polyvinyl alcohol and the optimal nanocomposite was obtained by Polymer Laboratories (PL)-TGA. The tensile property measurement was performed in a Zwick/Roell tester (Germany) at a crosshead speed of $50 \mathrm{~mm} / \mathrm{min}$ at $25^{\circ} \mathrm{C}$ as ASTM D 638 . The average values of three test results are reported.

\subsection{Antibacterial test}

The antibacterial properties of the prepared samples against standard Gram-positive bacteria (Lactobacillus and Staphylococcus aureus) as well as Gram-negative bacteria (Salmonella and Escherichia coli) were studied. In this method, first $100 \mathrm{ml}$ of broth nutrient culture was mixed with a lump of Resazurin (Camlab Chemicals, CB4WE) and distributed in $2 \mathrm{ml}$ culture holes. Broth nutrient has the same composition as the agar nutrient, but it lacks agar. Each of the polymers was added to cover the surface. Then, 0.5 McFarland bacteria were added to each of the holes. If the bacteria grow, Resazurin will lose its color as a result of the activity of the bacteria's recovering enzyme called nicotinamide adenine dinucleotide. If the blue color is maintained, it indicates the maintenance of the antibacterial property, or it shows that the bacteria have not grown. After incubation at a temperature of $37^{\circ} \mathrm{C}$ for $24 \mathrm{~h}$, the optical densities of the samples were measured using spectrophotometry, and the respective chart is drawn.

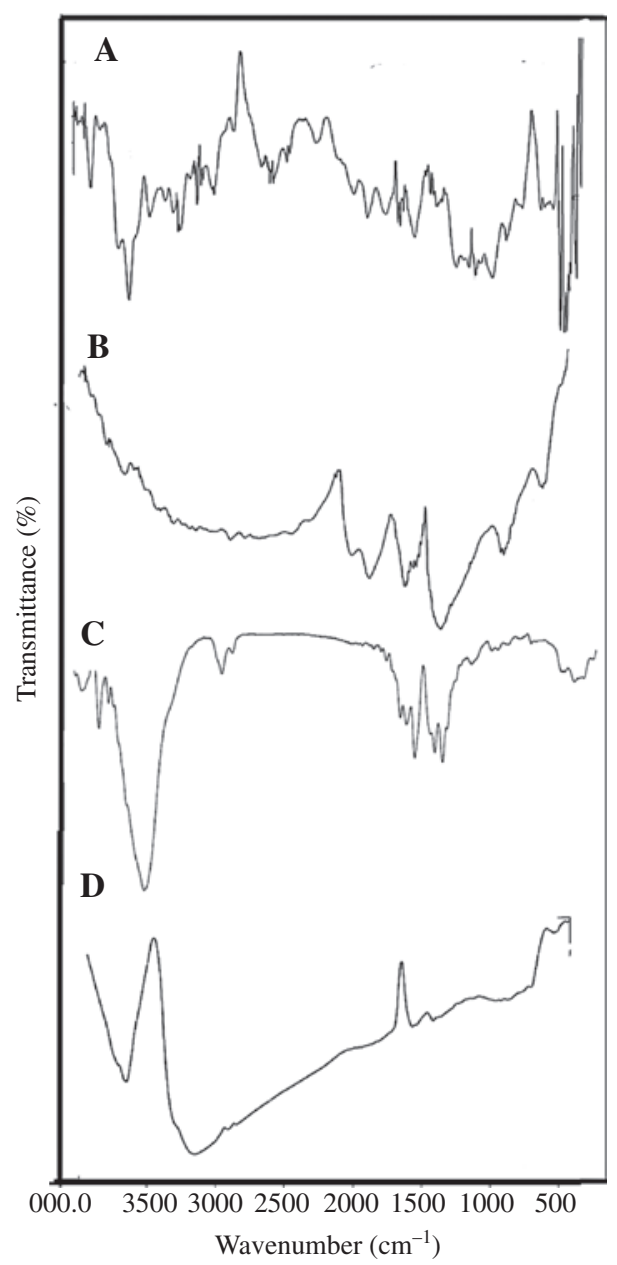

Figure 1: Fourier-transform infrared (FTIR) spectrum of (A) silver, (B) polyaniline, (C) polyvinyl alcohol and (D) sample 5. 


\section{Results and discussion}

\subsection{FTIR spectroscopy}

The FTIR spectrum of silver nanoparticles is shown in the curve in Figure 1A. The adsorption band at $3447 \mathrm{~cm}^{-1}$ is related to the $\mathrm{O}-\mathrm{H}$ stretching vibration, and the adsorption band at $1550 \mathrm{~cm}^{-1}$ is assigned to the $\mathrm{C}=\mathrm{C}$ bond [15].

In the FTIR spectrum of pure polyaniline in the curve in Figure $1 \mathrm{~B}$, the absorption peaks at $1490 \mathrm{~cm}^{-1}$ and $1580 \mathrm{~cm}^{-1}$ are attributed to the $\mathrm{C}$-C stretching mode of benzenoid and quinoid rings in polyaniline chains, respectively. The peaks at wavenumbers of $1293 \mathrm{~cm}^{-1}$ and $3600 \mathrm{~cm}^{-1}$ are assigned to the C-N and $\mathrm{N}-\mathrm{H}$ stretching bonds of the secondary amine group, respectively [13].

In the FTIR spectrum of polyvinyl alcohol in the curve in Figure 1C, the peak in the adsorption area of $3442 \mathrm{~cm}^{-1}$ is related to the stretching vibration of $\mathrm{O}-\mathrm{H}$, and the peak in $2925 \mathrm{~cm}^{-1}$ belongs to the stretching vibration of aliphatic $\mathrm{C}-\mathrm{H}$. Moreover, the peaks at $1740-1640 \mathrm{~cm}^{-1}$ are related to the stretching vibrations of $\mathrm{C}=\mathrm{O}$ and $\mathrm{C}-\mathrm{O}$ bonds left from acetate groups in polyvinyl alcohol (in reaction to the preparation of alcohol polyvinyl from polyvinyl acetate) [16].

In the curve in Figure 1D, the FTIR spectrum for nanocomposite of polyvinyl alcohol- polyaniline-silver (sample 5) is shown. It clearly reveals the major peaks associated with three components of the nanocomposite. In the analysis of the FTIR spectrum of this nanocomposite, the adsorption bands at $1398 \mathrm{~cm}^{-1}$ and $1540 \mathrm{~cm}^{-1}$ belong to the $\mathrm{C}$-C stretching mode of benzenoid and quinoid rings in polyaniline chains. Moreover, the adsorption peak observed at $2935 \mathrm{~cm}^{-1}$ indicates the stretching vibration of $\mathrm{O}-\mathrm{H}$ of silver and polyvinyl alcohol. The obtained results show that the three components of the nanocomposite exist in a compatible mode in the structure of the nanocomposite.

\subsection{SEM with energy dispersive X-ray analysis}

In Figure 2, the SEM images of the nanocomposite film of polyvinyl alcohol-polyaniline- silver (sample 5) are shown at different magnified sizes. As observed in the images, the nanoparticles of silver were immersed in the polymer matrix.

Figure 3 shows the energy dispersive X-ray (EDX) spectrum of the nanocomposite of polyvinyl alcohol-polyaniline- silver (sample 5). Attached Table in figure 3 gives the element composition of the nanocomposite. On examining the EDX spectrum, the amounts of the elements (carbon, oxygen, nitrogen, silver, etc.) and their wt $\%$ in sample 5 of the nanocomposite are shown.

According to this spectrum, $2.17 \%$ of silver was identified in the nanocomposite. Moreover, the distribution of the elements in one point of the nanocomposite is shown in Figure 4, which proves the good distribution of elements in this synthesized material.

\subsection{Results of antibacterial test}

According to Section 2.9, blue Resazurin was used to study the antibacterial properties of the prepared samples.
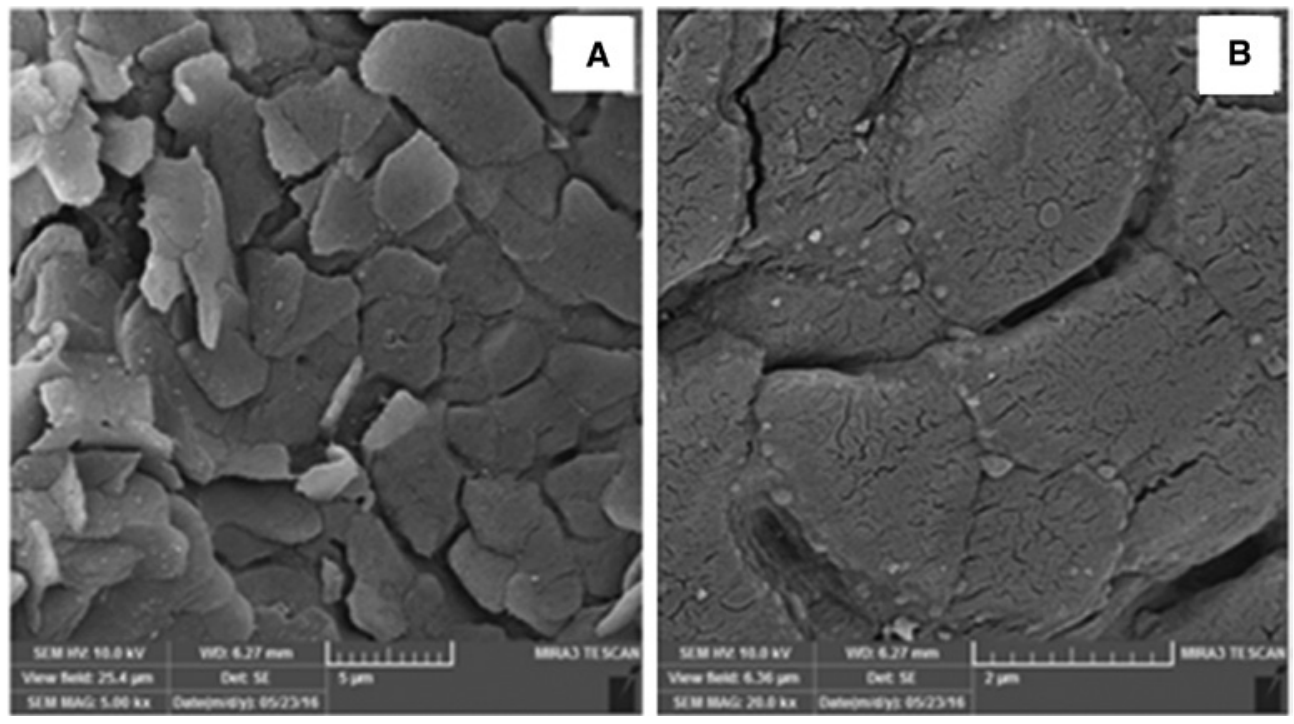

Figure 2: Scanning electron microscopy (SEM) images of sample 5 (A) $5 \mu \mathrm{m}$ and (B) $2 \mu \mathrm{m}$. 


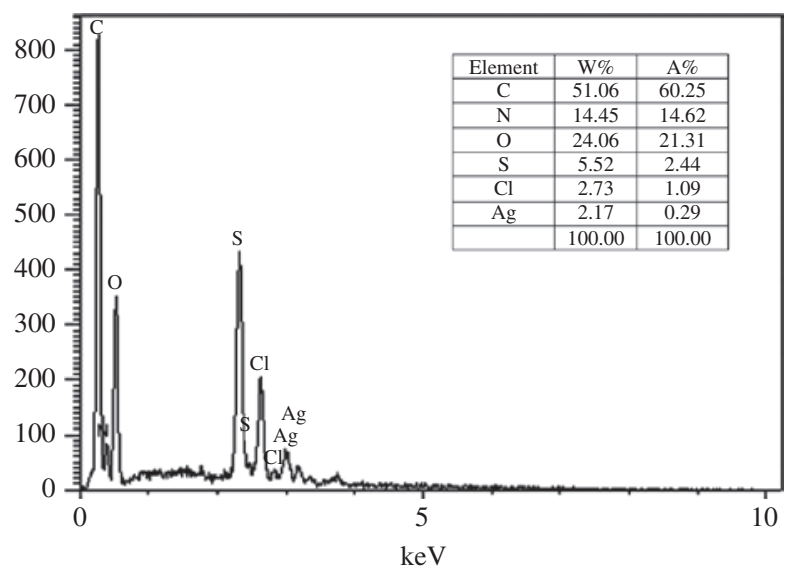

Figure 3: Energy dispersive X-ray (EDX) pattern and chemical composition of sample 5 .

The results are shown in Figure 5. After incubation at a temperature of $37^{\circ} \mathrm{C}$ for $24 \mathrm{~h}$, it was observed that samples 6, 7, 11, and 12 had antibacterial effects on Lactobacillus, S. aureus, Salmonella and E. coli bacteria.
According to the results, the antibacterial property of the samples is improved by increasing the wt $\%$ of the nanoparticle. In other words, the samples with high wt $\%$ of silver nanoparticles show stronger antibacterial properties than the others. Of course, because of the darkness of the polymer samples, the color change was not visible with the naked eye. Therefore, using spectrophotometry, the color change in Resazurin was evaluated, and the results are given in the form of a graph (Figure 6). As an antibiotic, ampicillin (with a concentration of $100 \mu \mathrm{g}$ in $1 \mathrm{ml}$ ) was used for negative and positive control without adding the polymer samples. Moreover, according to Figure 6, it can be concluded that the antibacterial effects were more effective on Gram-negative bacteria than the others. Although a precise mechanism has not been offered for justifying the antibacterial effects of the nanoparticles, the reported results indicate that the nanoparticles of silver show the highest antibacterial property against $E$. coli bacteria, and they were less effective against $S$. aureus, which is in line with the obtained results [17]. In other words, Gram-positive bacteria of $S$. aureus showed
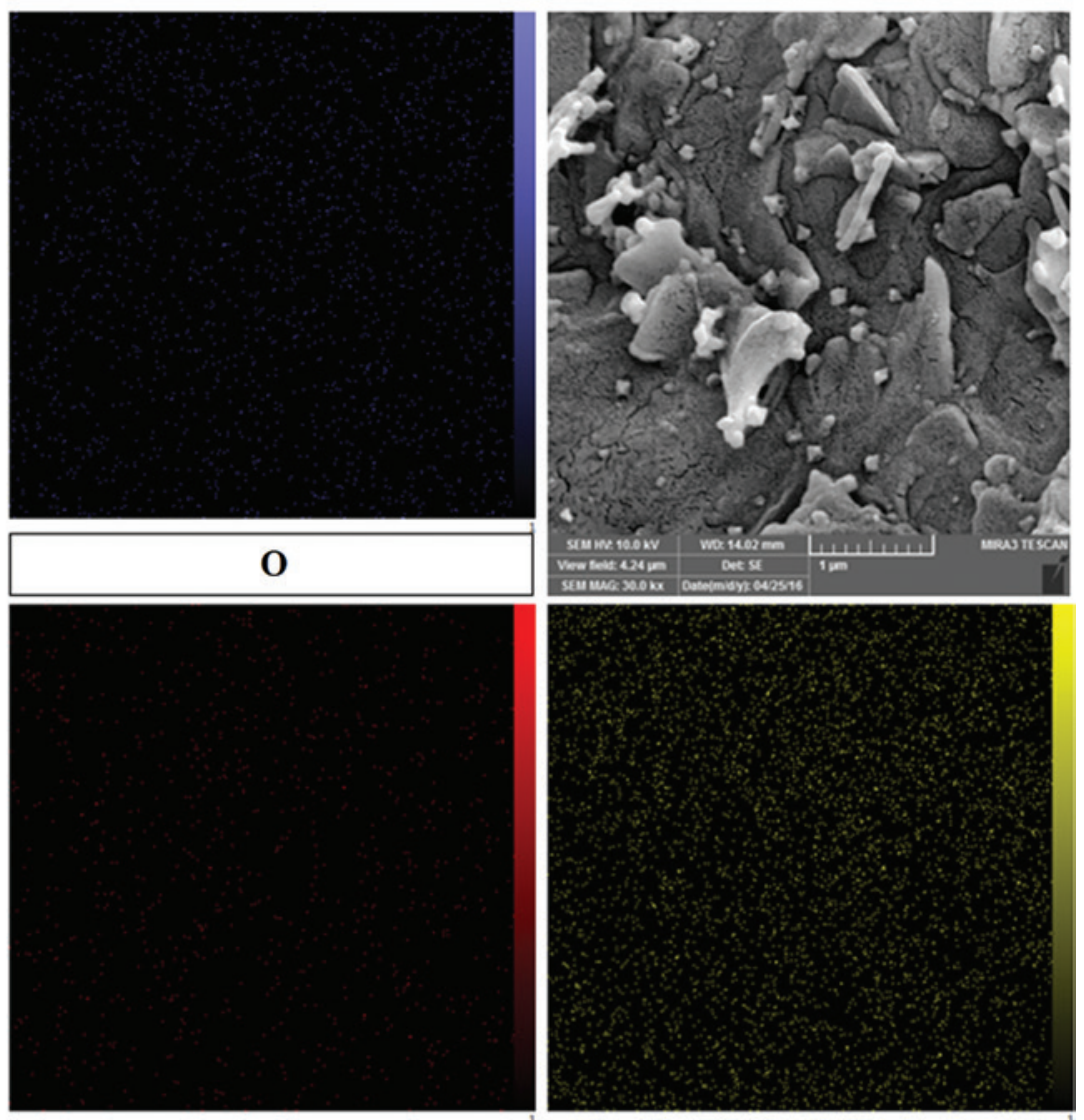

Ag

\section{C}

Figure 4: Scanning electron microscopy (SEM) image and energy dispersive X-ray (EDX) dot-mapping of sample 5. 


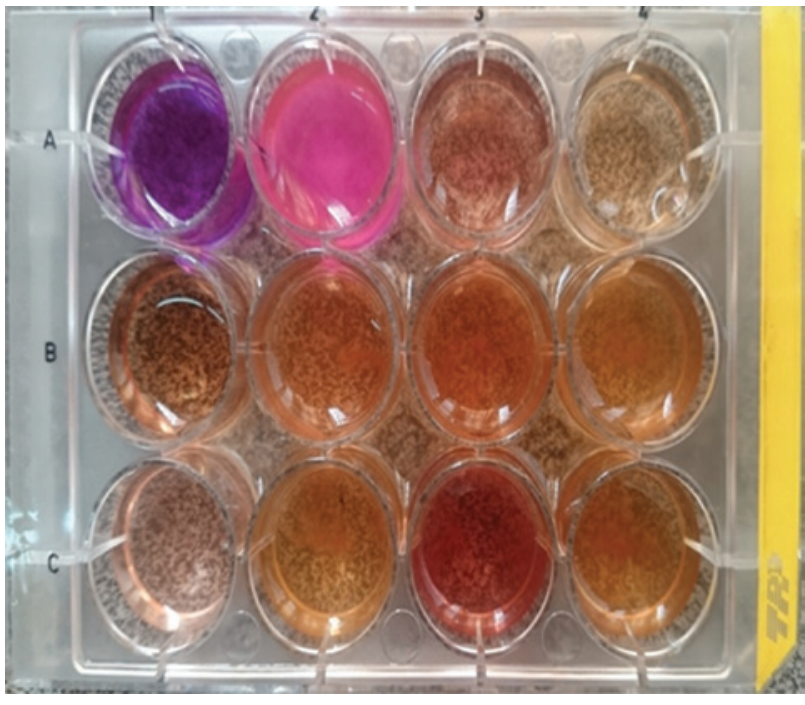

Figure 5: Changes of samples color in Resazurin antibacterial test.

more resistance than the Gram-negative bacteria of $E$. coli. This may be due to the difference in the cell walls of the Gram-positive and Gram-negative bacteria.

\subsection{Results of TGA test}

The TGA curves of silver nanoparticles, pure polyaniline, polyvinyl alcohol and the nanocomposite of polyvinyl alcohol-polyaniline-silver (sample 5) under a heating rate of $10^{\circ} \mathrm{C} \mathrm{min}^{-1}$ are shown in Figure 7. The results show that silver nanoparticles are very stable and weight loss is not observed in the temperature range of $50-700^{\circ} \mathrm{C}$. The results indicate that the initial mass loss of polyaniline at temperature ranges of $200-300^{\circ} \mathrm{C}$ is due to removal of solvent or dopant anions and decomposition of oligomers.
Also, the weight loss occurring around $400^{\circ} \mathrm{C}$ is due to the decomposition of the polyaniline chains.

In the TGA graph of polyvinyl alcohol, there is an intense weight loss $(80 \%)$ between $200^{\circ} \mathrm{C}$ and $450^{\circ} \mathrm{C}$ which happens due to the decomposition of the polymer chains and destruction of the polymer structure. A comparison of the TGA graph of the nanocomposite of polyaniline- polyvinyl alcohol-silver with the TGA graph of the pure polyaniline, polyvinyl alcohol and pure silver nanoparticles shows that up to $250^{\circ} \mathrm{C}$, the weight loss pattern is similar to polyvinyl alcohol and is very steep. It should be mentioned that $70 \%$ of this sample includes polyvinyl alcohol. From $250^{\circ} \mathrm{C}$ to $450^{\circ} \mathrm{C}$, the weight loss of the nanocomposite falls considerably, and the nanocomposite shows good thermal resistance. Above a temperature of $450^{\circ} \mathrm{C}$, the nanocomposite has better thermal resistance in comparison with the pure polymers. It seems that the silver nanoparticle (with $3 \mathrm{wt} \%$ ) has improved the thermal resistance of the nanocomposite.

\subsection{Results of tensile test}

The tensile measurements of polyvinyl alcohol-polyaniline-silver nanocomposites were performed according to ASTM (D-638-08). Figure 8 shows stress-strain curves of the films of polyvinyl alcohol-polyaniline-silver nanocomposites. The experimental data extracted from stressstrain curves of the samples are given in Table 2.

Based on the data in Table 2, the tensile strength of pure polyvinyl alcohol (sample 1) is $33.63 \mathrm{MPa}$. The prepared polyvinyl alcohol-polyaniline composite by adding $10 \mathrm{wt} \%$ and $20 \mathrm{wt} \%$ of polyaniline to pure polyvinyl alcohol (samples 8 and 9) leads to a sudden fall in tensile strength. This is because of very weak mechanical

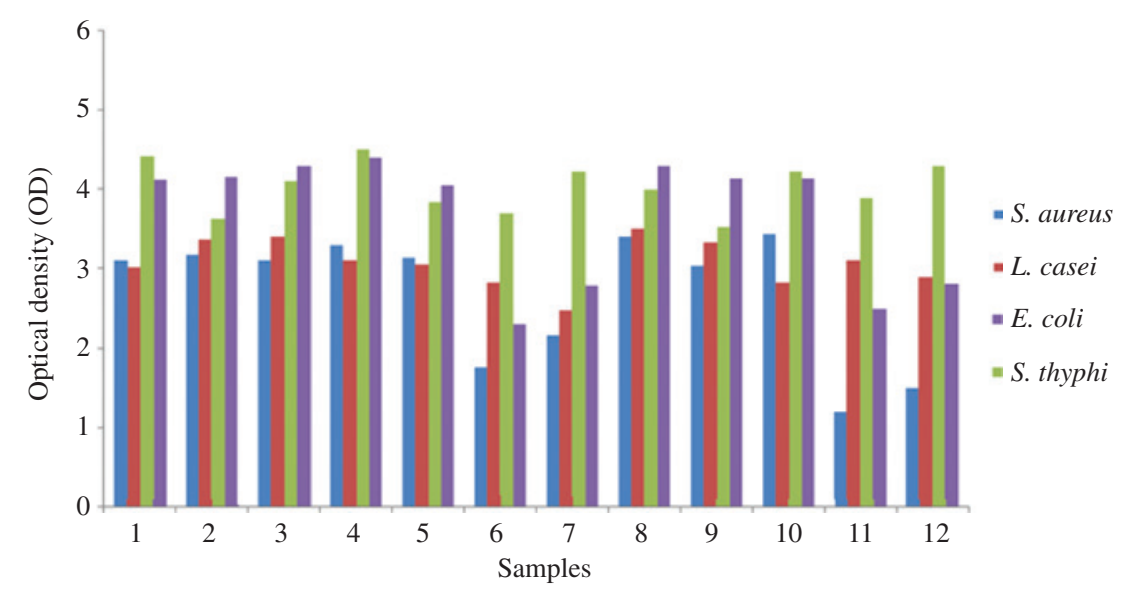

Figure 6: Antibacterial effects of the prepared samples according to Table 1. 


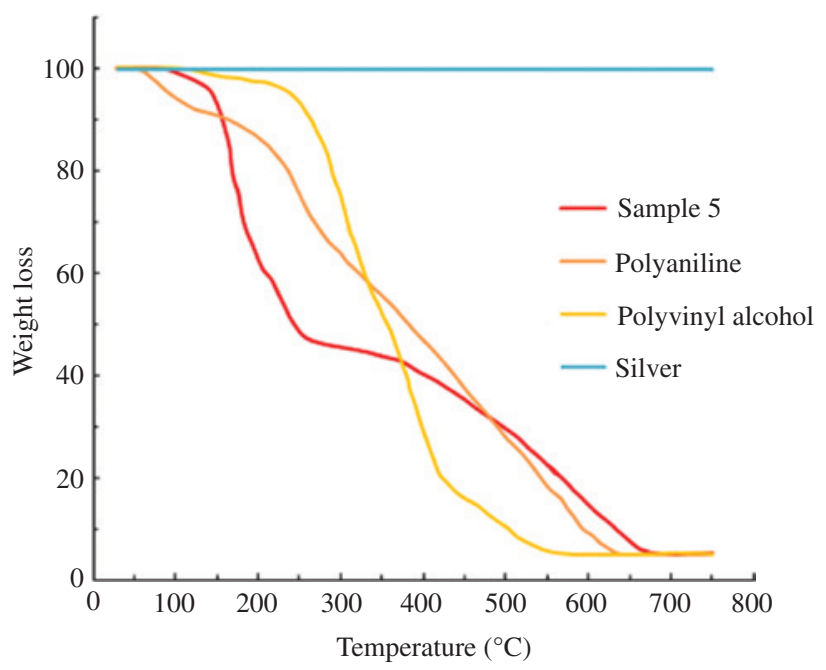

Figure 7: Thermogravimetric analysis (TGA) curve of polyaniline, polyvinyl alcohol, silver and sample 5 .

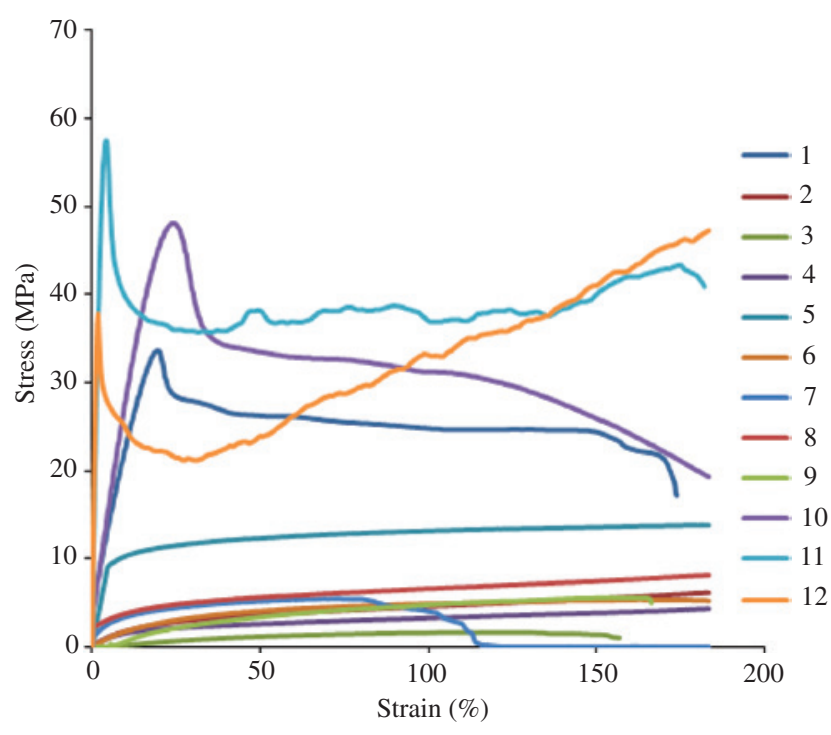

Figure 8: Stress-strain curves of the prepared samples according to Table 1.

properties and non-processability of polyaniline. With an increase in the wt $\%$ of polyaniline from $10 \mathrm{wt} \%$ to $20 \mathrm{wt} \%$, there would be greater fall in tensile strength.

Moreover, the prepared polyvinyl alcohol-silver nanocomposites by adding $1 \mathrm{wt} \%, 3 \mathrm{wt} \%$ and $5 \mathrm{wt} \%$ of silver to pure alcohol polyvinyl (samples 10-12) causes higher tensile strength, especially in sample 11 with a wt $\%$ of 3 for silver. Therefore, in this set of nanocomposites, polyvinyl alcohol-silver nanocomposite with a wt $\%$ of 3 for silver nanoparticles is the optimal nanocomposite, and the nanocomposites with wt $\%$ of 1 and 5 are in the next ranks.
Table 2: The mechanical properties of the prepared samples.

\begin{tabular}{lrrr}
\hline Samples & $\begin{array}{r}\text { Young's modulus } \\
(\mathrm{MPa})\end{array}$ & $\begin{array}{r}\text { Elongation } \\
\text { at break (\%) }\end{array}$ & $\begin{array}{r}\text { Tensile strength } \\
(\mathrm{MPa})\end{array}$ \\
\hline 1 & 2.03 & 166.50 & 33.63 \\
2 & 0.18 & 179.50 & 6.06 \\
3 & 0.02 & 155.25 & 1.60 \\
4 & 1.96 & 180.25 & 13.81 \\
5 & 0.19 & 179.75 & 4.25 \\
6 & 0.17 & 179.5 & 5.44 \\
7 & 0.55 & 175.50 & 5.31 \\
8 & 0.09 & 177.50 & 8.20 \\
9 & 0.08 & 161.25 & 5.55 \\
10 & 2.40 & 180.75 & 48.06 \\
11 & 16.51 & 179.25 & 57.45 \\
12 & 25.36 & 178.25 & 37.80 \\
\hline
\end{tabular}

Based on the values given in Table 2, in each set of the three-part nanocomposites with similar wt $\%$ of silver nanoparticles, the highest rate of tensile strength was recorded for the nanocomposites with polyvinyl alcohol $\mathrm{wt} \%$ of $87-90$ and polyaniline wt $\%$ of $8-10$. The decrease in the wt $\%$ of polyvinyl alcohol or increase in the wt $\%$ of polyaniline caused a fall in the values of tensile strength. Therefore, the optimal values for the $\mathrm{wt} \%$ of polyvinyl alcohol and polyaniline in the prepared nanocomposites are at the range of $87-90$ and $8-10$, respectively. Moreover, the comparison of the values of tensile strength in Table 2 shows that the highest rate of tensile strength was recorded for the nanocomposite with a wt $\%$ of 3 for silver nanoparticles, and the nanocomposites with $1 \mathrm{wt} \%$ and $5 \mathrm{wt} \%$ are in the next ranks. Therefore, the optimal value for silver nanoparticles is $3 \mathrm{wt} \%$, and the nanocomposite of sample 5 is considered as the optimal state.

Based on the values recorded in Table 2, the trend of changes for the values of elongation at break of the composites of polyvinyl alcohol-polyaniline, the nanocomposites of polyvinyl alcohol-silver, and the nanocomposites of polyvinyl alcohol-polyaniline-silver are similar to the values of tensile strength. The highest rate of elongation at break was related to the samples in which the wt $\%$ of polyvinyl alcohol was the highest.

The comparison of the values in Young's modulus also shows that all of the obtained samples, except the nanocomposites of polyvinyl alcohol-silver, have less Young's modulus than pure polyvinyl alcohol. The decrease in Young's modulus implies the increase in the flexibility of the obtained films. Conversely, the high rate of Young's modulus indicates the hardness and roughness of the film, and such a film resists against elasticity and elongation. 


\section{Conclusion}

In order to improve the thermal stability, processability, mechanical and antibacterial properties of polyaniline, nanocomposites of polyaniline-polyvinyl alcohol-silver were prepared. In order to study the effect of the components of the nanocomposite on its physicochemical and antibacterial properties, different $\mathrm{wt} \%$ of polyaniline, polyvinyl alcohol and silver were used.

To characterize the composition and structure of polyaniline-polyvinyl alcohol-silver nanocomposite, FTIR spectroscopy and SEM-EDX techniques were used. The SEM images recorded for the nanocomposite in the optimal state and EDX analysis for determining the value of its components as well as their distribution in the nanocomposite showed that silver nanocomponents are well distributed all over the film and are seen in the form of shining points.

Also, to study the thermal stability of polyaniline-polyvinyl alcohol-silver nanocomposite, TGA was used. The results from TGA tests showed that the presence of silver and polyaniline nanocomponents in the structure of the nanocomposite of polyaniline-polyvinyl alcohol polyvinyl-silver improves its thermal resistance to pure alcohol polyvinyl at high temperature.

The Resazurin antibacterial test confirmed the antibacterial properties of the prepared nanocomposites.

Examination of the mechanical properties of the prepared nanocomposites showed that the decrease in the wt $\%$ of polyvinyl alcohol or increase in the wt $\%$ of polyaniline causes a decrease in the value of tensile strength. Moreover, the nanocomposites with a wt $\%$ of 3 for silver nanoparticles, have the highest value of tensile strength.

\section{References}

[1] Araujo JR, Adamo CB, Costa e Silva MV, De Paoli MA. Polym. Compos. 2013, 34, 1081-1090.

[2] Nooshabadi MS, Ghoreishi SM, Behpour M. Electrochim. Acta 2009, 54, 6989-6995.

[3] Tsotra P, Friedrich K. Synth. Met. 2004, 143, 237-242.

[4] Mirmohseni A, Oladegaragoze A, Farbodi M. Iran. Polym. J. 2008, 17,135-140.

[5] Asma B, Afzal M, Akhtar J, Nadeema M, Hassan MM. Curr. Appl. Phys. 2010, 10, 601-606.

[6] Ghaffari-Moghaddam M, Eslahi H. Arabian J. Chem. 2014, 7, 846-855.

[7] Yavuz AG, Uygun A, Bhethanabotla VR. Carbohydr. Polym. 2009, 75, 448-453.

[8] He Z, Xiong L, Liu W, Wu X, Chen S, Huang K. J. Cent. South Univ. Technol. 2008, 15, 214-217.

[9] Wu T, Lin Y. Polymer 2006, 47, 3576-3582.

[10] Bourdo SE, Viswanathan T. Carbon 2005, 43, 2983-2988.

[11] Srivastav N, Singh Y, Singh RA. Bull. Mater. Sci. 2011, 34, 635-638.

[12] Gupta K, Jana PC, Meikap AK. Synth. Met. 2010, 160, 1566-1573.

[13] Olad A, Nosrati R. Prog. Org. Coat. 2013, 76, 113-118.

[14] Olad A, Barati M, Behboudi S. Prog. Org. Coat. 2012, 74, 221-227.

[15] Mohd Rafie J, Roslina A. Int. J. Electrochem. 2012, 7, 5596-5603.

[16] Reis EF, Campos FS, Lage AP, Leite RC, Heneine LG, Vasconcelos WL, Mansur HS. Mater. Res. 2006, 9, 185-191.

[17] Alimohammadi F, Montazer M, Shamei A, Rahimi MK. Iran. J. Polym. Sci. Technol. 2012, 25, 265-275. 